\section{REFERENCES}

Committee on Planning for Catastrophe. 2007. Successful Response Starts with a Map: Improving Geospatial Support for Disaster Management, National Research Council. Washington, DC: National Academies Press. doi: $10.17226 / 11793$.

Frerichs, R. R., P. S. Keim, R. Barrais, R. Piarroux. 2012. "Nepalese origin of cholera epidemic in Haiti." Clinical Microbiology and Infection 18: E158-E163. doi: 10.1111/j.1469-0691.2012.03841.x.

Frerichs, Ralph R. 2017. "John Snow - A Historical Giant in Epidemiology.” Accessed October 21, 2017. http:// www.ph.ucla.edu/epi/snow.html.
Gladstone, Rick. 2016. "Poor Sanitation Persisted at U.N. Missions Long After Haiti Cholera Crisis.” New York Times, August 19, 2016. https://www.nytimes. com/2016/08/20/world/americas/haiti-cholerasanitation-un-peacekeepers.html?_r=0.

\section{Haggett, Peter, 2000. The Geographical Structure of} Epidemics. Oxford: Oxford University Press.

Koch, Tom, and Kenneth Denike. 2009. "Crediting his Critics' Concerns: Remaking John Snow's Map of Broad Street Cholera, 1854.” Social Science E̋ Medicine 69(8): 1246-1251. doi: 10.1016/j. socscimed.2009.07.046.

Koch, Tom. 2000. Disease Maps: Epidemics on the Ground. Chicago: University of Chicago Press.

2016. Cartographies of Disease, Expanded Edition. Redlands, CA: Esri Press.

\title{
CARTOPHILIA: MAPS AND THE SEARCH FOR IDENTITY IN THE FRENCH-GERMAN BORDERLAND
}

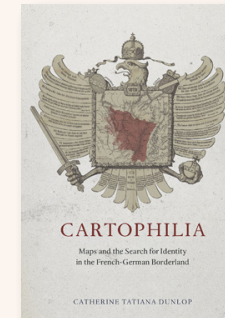

By Catherine Tatiana Dunlop

The University of Chicago Press, 2015

257 pages, 16 color plates, 71 halftones (primarily maps), $\$ 45.00$, hardcover.

ISBN: 978-0-226-17302-3

\section{Review by: Leslie Wagner}

Cartophilia: Maps and the Search for Identity in the FrenchGerman Borderland, focuses on the representation of the Alsace-Loraine region on European maps in the eighteenth and early nineteenth centuries. The author also provides an introduction which offers a general overview of the cartographic aspects she discusses, and an epilogue addressing changes that have been seen-and can be anticipated-since the period covered in the book.

Part I, "Mapping Borders," consists of three chapters. The first, "States Map Their Borders," examines cartography from a national viewpoint. The second chapter, "What Makes a Good Border?” provides an interesting discussion of natural and imposed boundaries. The third, "Language
Maps," demonstrates the use of regional language and/or local dialect to distinguish the appropriate placement of national boundaries, along with the reactions and consequences at national levels.

Part II of Cartophilia represents the bulk of the book, and is devoted to close examination of the varied cartography of the Alsace-Loraine region and of its central city, Strasbourg. It particularly examines the development of regional identity in Alsace-Loraine as it progressed from a landscape of insular villages into a unified region centered on the cathedral city of Strasbourg. Dunlop thoroughly discusses the ebb and flow of French and German influence as they alternately exerted control over the region. The late nineteenth century also saw the rise of the bourgeois class, which brought changes in personal and social activities; in particular, the development of tourism. This resulted in the incorporation of regional landmarks and memorials into maps and other visual materials, and also spurred the growth of private organizations devoted to supporting touristic pursuits, further encouraging the blending of cultures. In Chapter 4, "Finding the Center," the author explores regional identity and the concept of a regional homeland (as distinct from a national identity), 
and how it affects communal perspectives on regional development. These concepts are closely tied with the difficulties that late nineteenth-century Germany had in projecting its own conception of Heimat, or homeland, into the Alsace-Loraine region. The introduction of geography into the region's German educational curriculum was seen as one remedy. It was thought that the concept of Heimatort, or hometown, would allow students to identify with their own unique village or town while at the same time conveying the idea of being a part of both a unified region and a greater, national whole.

In Chapter 5, "Maps for Movement," Dunlop brings us to the Vosges Mountains and to their role in the push and pull between French and German culture and nationalism. More than just a physical feature in the landscape, or a potential national boundary (as it was between 1871 and 1918), the Vosges were frequented by both locals and visitors from afar. These ramblers were encouraged by materials produced both by "citizen mapmakers" and organizations that produced maps of walking or hiking trails that often featured tranquil, scenic views.

It occurs to me that this well-established practice of hiking through the region-with its clubs, formal routes, and organized walks in the Vosges Mountains-was quite possibly a precursor to the modern-day Volksmarch organization. These days, Volksmarch participants receive a medal for completion of their chosen distance, and I highly prize the Schloss Neuschwanstein medal from the Volksmarch event in which I participated during the late 1970s.

The bucolic atmosphere takes a turn, however, with the advent of World War I. In that conflict, the Vosges Mountains saw almost constant fighting and many destructive battles. After the war, however, both the French and German citizenry of the region banded together to repair the landscape, memorialize the battlegrounds, and provide special access to the battlefields-which were already being visited by thousands of people. Dunlop refers to the area as a "martyred landscape."

Chapter 6, "Visualizing Strasbourg," introduces us to Strasbourg - the regional capital of Alsace-Lorraine-and to its central role in the territorial dispute between France and Germany. Strasbourg was built at the confluence of several ancient Roman roads where they crossed the Rhine River, another major regional thoroughfare. Dunlop particularly notes the role of the Cathedral of Strasbourg, which provides impressive views of not only the city but of the entire region and beyond. Strasbourg Cathedral was deemed the tallest building in the world from 1647-1874, and has an observation deck upon which visitors can stand and peer around with awe: east to the Black Forest deep in Germany, south as far as Switzerland, and westward toward France and the Vosges Mountains.

The Rhine River and the city of Strasbourg served as a bulwark that the French frequently defended, and the city, which suffered frequently in battle, was depicted on maps as a fortress. Nonetheless, there were times when French and German governing bodies worked together, as when Napoleon III and leadership from the German state of Baden completed a bridge over the Rhine River for expanding railway lines.

The "trend toward fluid borders," as Dunlop phrases it, came to a halt from 1871 until 1918, when Strasbourg was handed over to exclusive German rule as a result of the 1870 Franco-Prussian War. During the war, the Germans had ruthlessly shelled civilian targets throughout Strasbourg, but once the city surrendered, the German army itself, as well as an influx of German civilians, brought on a program of rebuilding and expansion. This did not, however, unite the indigenous Alsatians with the invading Germans, who not only occupied the area as conquerors, but made their homes in Strasbourg, changing the city's appearance with new construction that was definitively German. It was only after 1910 that Alsatians were again able to have a say in the construction of new buildings, and to slowly put a halt to the German stamp that was pressed on the city over the four preceding decades. The concept of a regional Heimat was once again brought into play, albeit briefly, to return Strasbourg to its former uniqueness.

Once again, however, violent conflict put a stop to progress with the start of World War I. Afterwards, the region having returned once more to French control, the people of Alsace-Loraine were able to again work together toward their future: concentrating on port development along the Rhine River and establishing a permanent French foothold in the region. Although World War II again brought destruction to Strasbourg, I recall passing through Strasbourg in the early 1960s, by which time the ravages of World War II had been repaired. The city was once again bustling with industry and had regained its position as a major port on the Rhine. 
In the book's epilogue, Dunlop provides an interesting perspective on a cartographic exhibition in Paris, $L a$ France en relief, which ran from January 18-February 17, 2012. She also briefly discusses the radical changes Europe has witnessed since the era she explores in Cartophilia, and how these developments might affect regional evolution and the European map.

Well written, thoughtful, thorough, and detailed, Dunlop's work introduces the reader to broad, inter-related concepts of regional and national identity before narrowing its focus to their development as seen in the region of Alsace-Loraine as it existed under both French and German rule. Dunlop applies French, German, and Alsatian cartographic perspectives to her observations on the creation and re-creation of boundaries and map content for the region. Her discussion of the development of educational geography under German rule was of particular interest.

Dunlop delves into the complex relationship between conflict and culture, and provides evidence of how their interweaving affected the area. The changes caused by the influence of French and German rule over Alsace-Loraine is reflected in the maps and materials produced over time, and can be seen in the way these maps and their contents evolved with changes in national dominance.

She discusses the wedge that violent conflict places between nations, and between individuals within a region, as well as the part played by a legacy of conflict in reuniting a region. This two-fold role is, in many ways, a surprising concept: we are familiar with the gaping wounds between oppositional forces that are brought about by war, but we do not usually consider the healing of those wounds and the reunification of enemies as fellow citizens once again. At some point a region must declare that enough is enough: that its people must rise above their differences and strive to work together to rebuild their lives and futures. In her epilogue, the author reminds us of the enormous changes that have occurred, not only just after World War II, but even during the 1970s and 1980s. Will new developments in mapmaking influence trends toward regional thinking? Will these, in turn, overtake national concepts?

I, myself, lived in the northern portion of the AlsaceLorraine region as a young child, and later made a brief return visit along the French-German border in the 1970s while living in Germany as a military spouse. Stopping in the first small town to the west of the Rhine, we made a choice of restaurant in which to dine. My rusty highschool French, however, was not enough to bring a welcome from the staff. In the end, a woman who spoke both German and French was brought from the kitchen and through her we managed to communicate our order. Cartophilia gave me a new outlook on that interesting cultural encounter; I had not, in truth, expected to find a bilingual speaker in France, given the attitudes the French seemed to have toward most outsiders. Only thirty years removed from World War II, I anticipated animosity on the part of the French towards Germans, and finding a local who spoke German as her first language was a particular surprise. I now realize it was only because we were in Alsace-Loraine, where French and German citizens have mingled for decades and continue to do so, forming the truly distinctive culture found in Alsace-Loraine.

Not only did Cartophilia bring a new understanding to my own brief experience in Alsace-Loraine, I found Dunlop's research extensive and deep, providing the reader with fine examples of maps and regional brochures placed in their cultural context. The concepts are well-explained, well-supported, and thought-provoking. Cartophilia is a particularly enjoyable read for anyone with an affinity for nineteenth- and twentieth-century France and Germany. 